Portland State University

PDXScholar

8-2009

\title{
Transferring Community-based, Active Transportation GIS Assessment Tools Nationwide
}

\author{
Marc Schlossberg \\ University of Oregon \\ Nico Larco \\ University of Oregon
}

Follow this and additional works at: https://pdxscholar.library.pdx.edu/trec_reports

Part of the Transportation Commons, and the Urban Studies and Planning Commons Let us know how access to this document benefits you.

\section{Recommended Citation}

Schlossberg, Marc and Nico Larco. Transferring Community-based, Active Transportation GIS Assessment Tools Nationwide. OTREC-TT-09-02. Portland, OR: Transportation Research and Education Center (TREC), 2009. https://doi.org/10.15760/trec.9

This Report is brought to you for free and open access. It has been accepted for inclusion in TREC Final Reports by an authorized administrator of PDXScholar. Please contact us if we can make this document more accessible: pdxscholar@pdx.edu. 


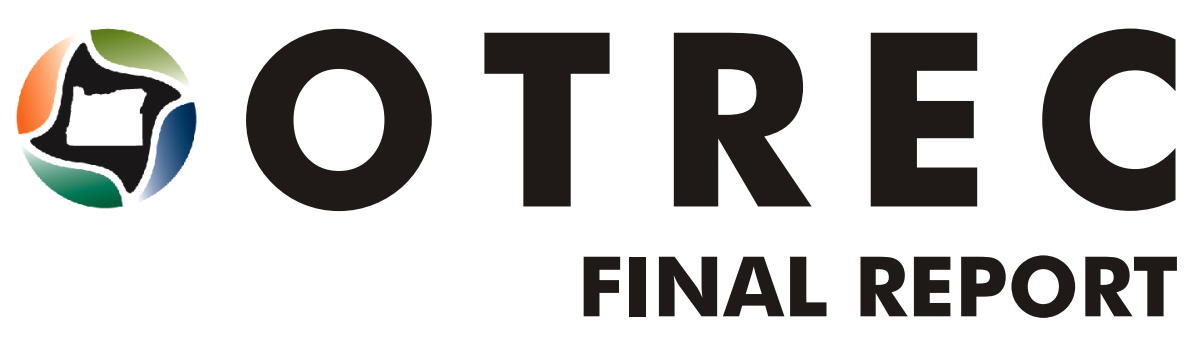

\section{Transferring Community-Based, Active Transportation GIS Assessment Tools Nationwide}

OTREC-TT-09-02

August 2009

A National University Transportation Center sponsored by the U.S. Department of Transportation's Research and Innovative Technology Administration 


\title{
TRANSFERRING COMMUNITY-BASED, ACTIVE TRANSPORTATION GIS ASSESSMENT TOOLS NATIONWIDE
}

\section{Final Report}

\section{OTREC-TT-09-02}

\author{
by \\ Marc Schlossberg \\ Nico Larco \\ University of Oregon \\ for \\ Oregon Transportation Research \\ and Education Consortium (OTREC) \\ P.O. Box 751 \\ Portland, OR 97207

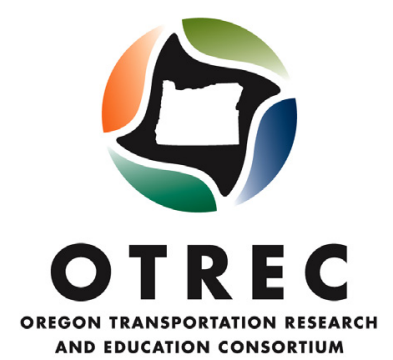

August 2009 



\section{Technical Report Documentation Page}

\begin{tabular}{|c|c|c|c|c|}
\hline $\begin{array}{l}\text { 1. Report No. } \\
\text { OTREC-TT-09-02 }\end{array}$ & \multicolumn{3}{|c|}{ 2. Government Accession No. } & 3. Recipient's Catalog No. \\
\hline \multicolumn{3}{|c|}{ 4. Title and Subtitle } & \multicolumn{2}{|c|}{$\begin{array}{l}\text { 5. Report Date } \\
\text { August } 2009\end{array}$} \\
\hline \multicolumn{4}{|c|}{ Transferring Community-Based, Active Transportation GIS Assessment Tools Nationwide } & 6. Performing Organization Code \\
\hline \multicolumn{3}{|l|}{$\begin{array}{l}\text { 7. Author(s) } \\
\text { Marc Schlossberg } \\
\text { Nico Larco }\end{array}$} & \multicolumn{2}{|c|}{ 8. Performing Organization Report No. } \\
\hline \multirow{2}{*}{\multicolumn{4}{|c|}{$\begin{array}{l}\text { University of Oregon } \\
1209 \text { University of Oregon } \\
\text { Eugene, OR } 97403-1209\end{array}$}} & 10. Work Unit No. (TRAIS) \\
\hline & & & \multicolumn{2}{|c|}{ 11. Contract or Grant No. } \\
\hline \multirow{2}{*}{\multicolumn{4}{|c|}{$\begin{array}{l}\text { Oregon Transportation Research } \\
\text { and Education Consortium (OTREC) } \\
\text { P.O. Box } 751 \\
\text { Portland, Oregon } 97207\end{array}$}} & 13. Type of Report and Period Covered \\
\hline & & & \multicolumn{2}{|c|}{ 14. Sponsoring Agency Code } \\
\hline \multicolumn{5}{|l|}{ 15. Supplementary Notes } \\
\hline \multicolumn{5}{|c|}{$\begin{array}{l}\text { "Livability" has recently been declared one of four top priorities by the Secretary of the U.S. Department of Transportation (USDOT), and the } \\
\text { USDOT, the Environmental Protection Agency (EPA), and the Department of Housing and Urban Development (HUD) have entered into an } \\
\text { historic partnership to address the issue. Ultimately, this term refers to the quality of life within one's community and the ease, comfort, and joy } \\
\text { with which one can access places he or she want to go. For most Americans, their neighborhoods have been designed to predominantly } \\
\text { accommodate the automobile, and more active forms of transportation such as walking and biking have been neglected }\end{array}$} \\
\hline \multicolumn{5}{|c|}{$\begin{array}{l}\text { Previous and current OTREC work has developed a suite of GIS tools focused on assessing these environments in a fine-scaled, field-based, } \\
\text { geo-referenced format so that local communities can better identify gaps in their networks and work to make appropriate improvements. This } \\
\text { work explicitly focuses on the role and capacity of a general citizenry to conduct built environment active transportation audits and engage in } \\
\text { facilitated discussions about the data and maps resulting from their community data collection. }\end{array}$} \\
\hline $\begin{array}{l}\text { Active Transportation, PPGIS, walkabili } \\
\text { environment, audit tool, complete streets }\end{array}$ & $\begin{array}{l}\text { ycle, pedestrian, built } \\
\text { routes to school }\end{array}$ & $\begin{array}{l}\text { 18. D } \\
\text { No } \\
\text { ww }\end{array}$ & $\begin{array}{l}\text { bution Statement } \\
\text { rictions. Copies av } \\
\text { trec.us }\end{array}$ & RE: \\
\hline $\begin{array}{l}\text { 19. Security Classification (of this report) } \\
\text { Unclassified }\end{array}$ & $\begin{array}{l}\text { 20. Security Classific } \\
\text { Unclassified }\end{array}$ & page) & $\begin{array}{l}\text { 21. No. of Pages } \\
42\end{array}$ & 22. Price \\
\hline
\end{tabular}




\section{ACKNOWLEDGEMENTS}

This project was funded by the Oregon Transportation Research and Education Consortium (OTREC) with additional support from the National Center for Biking and Walking (NCBW). We would like to express sincere appreciation for the support and leadership provided by NCBW's Gary McFadden and Bill Wilkinson, who have worked tirelessly for four decades with the singular goal of getting more people to bike and walk.

\section{DISCLAIMER}

The contents of this report reflect the views of the authors, who are solely responsible for the facts and the accuracy of the material and information presented herein. This document is disseminated under the sponsorship of the U.S. Department of Transportation University Transportation Centers Program and the NCBW in the interest of information exchange. The U.S. Government and the NCBW assume no liability for the contents or use thereof. The contents do not necessarily reflect the official views of the U.S. Government or the NCBW. This report does not constitute a standard, specification, or regulation. 


\section{TABLE OF CONTENTS}

EXECUTIVE SUMMARY \& REPORT CONTENT ............................................................... 1

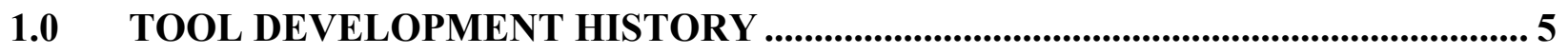

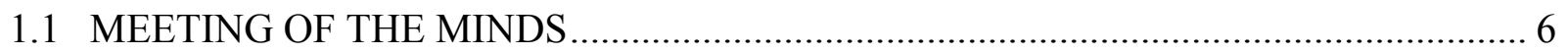

1.2 PERCEPTION, OBJECTIVE MEASURE, AND EVALUATION TOOL CONCEPT .... 8

1.3 PUBLIC AND PARTICIPATION IN GIS ASSESSMENTS ....................................... 10

1.4 HISTORY OF PILOT AUDITS TO DATE .............................................................. 12

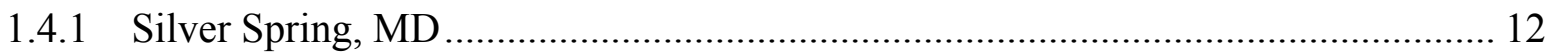

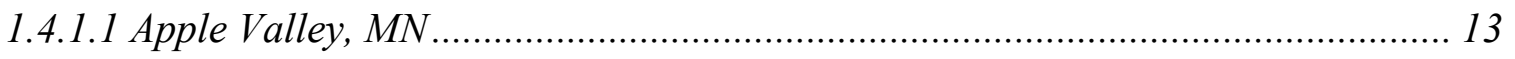

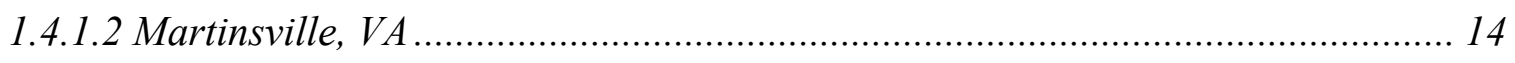

1.4.1.3 Communities and Schools Together (CAST) .............................................. 15

2.0 COST OF CONDUCTING AUDITS ............................................................. 17

3.0 DISTRIBUTION/DISSEMINATION MODELS................................................. 19

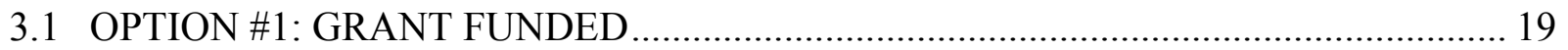

3.2 OPTION \#2: PUBLIC AGENCIES/LOCAL GOVERNMENT .................................... 20

3.3 OPTION \#3: LOCAL ADVOCACY GROUPS ...................................................... 20

3.4 OPTION \#4: NATIONAL ISSUE GROUPS ......................................................... 21

3.5 OPTION \#5: STATE/NATIONAL GOVERNMENT PROGRAMS............................. 22

3.6 OPTION \#6: "TRAIN THE TRAINER" MODEL ....................................................... 22

4.0 CHANGING THE MODEL: FROM CENTRALIZED TO DECENTRALIZED ... 27

4.1 PARTIALLY CENTRALIZED PARTIALLY DECENTRALIZED EXPERTISE

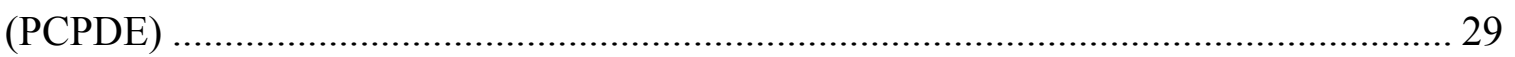

4.2 DECENTRALIZED DISTRIBUTED EXPERTISE (DDE) MODEL ............................ 31

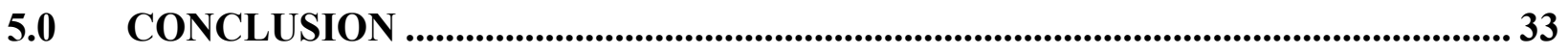

\section{LIST OF TABLES}

Table 1: Parameters of Built Environment Assessment Models. ... 27 


\section{LIST OF FIGURES}

Figure 1: Sample evaluation page of the Complete Streets Assessment Tool............................ 7

Figure 2: Basic Question Schema for CSAT ..................................................................... 9

Figure 3: Participants in a Complete Streets Assessment Workshop ...................................... 11

Figure 4: CAST Project, Bethel Neighborhood, Eugene, OR. ............................................... 16

Figure 5: CAST Project Flyer Advertising Complete Street Workshop..................................... 24 


\section{EXECUTIVE SUMMARY \& REPORT CONTENT}

"Livability" has recently been declared one of four top priorities by the Secretary of the U.S. Department of Transportation (USDOT), and the USDOT, the Environmental Protection Agency (EPA), and the Department of Housing and Urban Development (HUD) have entered into an historic partnership to address the issue. Ultimately, this term refers to the quality of life within one's community and the ease, comfort, and joy with which one can access places he or she want to go. For most Americans, their neighborhoods have been designed to predominantly accommodate the automobile, and more active forms of transportation such as walking and biking have been neglected

Previous and current OTREC work has developed a suite of GIS tools focused on assessing these environments in a fine-scaled, field-based, geo-referenced format so that local communities can better identify gaps in their networks and work to make appropriate improvements. This work explicitly focuses on the role and capacity of a general citizenry to conduct built environment active transportation audits and engage in facilitated discussions about the data and maps resulting from their community data collection.

Using hand-held Personal Digital Assistants (PDAs) to collect data, residents of a community can gather information about their streets, intersections, sidewalks, and facilities. This data can be translated - without the need for laborious analyses of paper data and spreadsheets - to easily understood maps showing various layers of the collected data. These maps can then be available to anyone within the community with access to an online browser.

Our experience has validated the potential of such public-participation GIS methods to promote active communities. However, it has become clear that the increasingly cumbersome, costly and technical nature of currently available GIS systems challenge the development of truly accessible and citizen-based mobile GIS tools.

This project report focuses on our three key issues: 1) cost of the existing model; 2) variations on transferring this technology that may offer more economical ways of distribution; and 3) an exploration of transitioning the data collection model from a GIS-based workshop approach to a fully distributed model that empowers any citizen with a "smart phone" to become assessors of their active transportation environment.

It may be that a mobile phone-based approach to assessing the built environment could energize large numbers of citizens across the country to take the USDOT Secretary's interest in "livability" and apply it in meaningful ways all across the country to help the nation transition from an urban form dependent on the automobile to one that offers more comprehensive transportation decisions that include walking and biking, the healthy, nonpolluting and congestion-reducing modes of transportation. 


\section{INTRODUCTION TO PROJECT/REPORT}

The last 10 years have seen a growing recognition of the importance that transportation policy and planning play in a variety of sustainability issues including a) energy conservation, b) land use and smart growth, c) air and water quality, and d) social equity and quality of life. As a result, communities across the nation are changing the way they view and approach transportation and community design. Once reserved only for the rapid passage of motorized vehicles, our roads and highways have increasingly been viewed as an important public space that supports multiple uses beyond that of automobile travel. This change in attitude has given rise to the concept of the "complete street." A complete street considers equally the importance of the pedestrian, the bicyclist, and the driver. A complete street can be used by a child walking to school, a senior using a walker, a cyclist commuting to work, or a driver delivering packages.

Communities across the nation are adopting complete-street policies that seek to improve the pedestrian, bicycle, and transit components of our street network while supporting other active transportation efforts such as Safe Routes to School. Many communities have begun transitioning towards this new (model or ideal?) of integrated, sustainable and equitable transportation, although there remains much debate about what makes a good walkable and bikeable environment. Yet few communities have any clear idea of what defines a complete street, how it is assessed, and how to think about a connected network of complete streets.

This transition has challenged communities, planners, and public officials to make decisions using transportation data and tools primarily designed around the needs of automobiles and their drivers. Planning and designing for active transportation and complete streets requires data specific to the added sensitivities of pedestrians and bicyclists - young, old, skilled and unskilled - and to the fine-scale features of their environments (e.g., sidewalks, road buffers, aesthetics, accessibility, and continuity).

Previous and current OTREC work has developed a suite of GIS tools focused on assessing these environments in a fine-scaled, field-based, geo-referenced format so that local communities can better identify gaps in their networks and work to make appropriate improvements. This work explicitly focuses on the role and capacity of a general citizenry to conduct built environment audits and engage in facilitated discussions about the data and maps resulting from their community data collection.

Using PDAs to collect data, residents of a community can gather information about their streets, intersections, sidewalks, and facilities. This data can be translated - without the need for laborious analyses of paper data and spreadsheets - to easily understood maps showing various layers of the collected data. These maps can then be available to anyone within the community with access to an online browser. 
Experience has validated the potential of such public-participation GIS methods to promote active communities. However, it has become clear that the increasingly cumbersome, costly and technical nature of current GIS systems challenges the development of truly accessible and citizen-based mobile GIS tools. Meanwhile, simultaneous to the development of these mobile GIS tools over the past five years, public exposure to and familiarity with geographic data has grown unexpectedly and exponentially through the emergence of popular online mapping software such as Google Maps. As this trend continues, online mapping will increasingly influence how transportation decisions are made, including those related to walking and biking. Yet, while applications like Google Maps are widely used to assist in transportation decisions, its routing is limited due to the lack of fine-scale, street-level detail around which pedestrian or bicyclist transportation decisions are made.

This project report focuses on past experience, successes, and limitations of leading community workshops around issues of complete streets (CS), Safe Routes to School (SRTS), and the Americans with Disabilities Act (ADA) using GIS as the primary delivery tool. There is no doubt that our citizen-led data gathering efforts have proven successful in the communities where they have been applied, as will be highlighted below. However, the ability for wider diffusion of innovation is limited due to cost and technical barriers. This report will therefore highlight the success and opportunities of the existing model of spatially-based participatory data collection as well as present potential opportunities in the growth of new online mapping and smart-phone technology. 


\subsection{TOOL DEVELOPMENT HISTORY}

The Complete Streets Assessment Tool (CSAT) is the culmination of several previous iterations of tools. An original suite focused on the pedestrian, bicycle and transit environments separate from one another. One of the original tools, the School Environment Assessment Tool (SEAT), was designed to focus solely on safe routes to school, whereas the CSAT was developed to target a city's transportation infrastructure more broadly. Eventually, through multiple tests, the two tools merged in form and function under the CSAT name.

The goal of the tool's development was to create a data entry method that could be used to assess various aspects of the built environment related to the walking and biking experience, and to have ordinary citizens be engaged and responsible for the actual data collection and analysis. The assessment tools would lead the user through a different set of questions based on some combination of the functional classification of the street segment and the surrounding land uses in order to streamline data collection to just those variables that would be relevant for a given typology of a city's area.

For instance, low-volume local roads often accommodate bicyclists in the "automobile" travel lane whereas arterials generally require a designated bike lane. And, one would expect different pedestrian facilities in a busy main street commercial area versus a remote industrial area on the outskirts of a city. Customizing the assessment tools based on these differences would keep the tools relevant in a general sense, but also would allow general citizen assessors to remain engaged as the questions would always be appropriate to the environment being assessed.

The resulting CSAT tool, thus, allows any member of the public, with only minimal training, to evaluate multiple aspects of the complete-streets concept, including assessing the pedestrian, bicycle and transit environment. The automobile environment was excluded because roads have largely already been optimized for drivers and the focus of this work is on improving active modes of transportation (walking and biking) as a strategy to meet national goals of reducing obesity, emissions and congestion along with increasing community livability. Each of these components included a mix of objective and subjective questions.

In addition to functional classification, the initial CSAT versions included an "off-street path" component to evaluate multiuse paths that may be separate from roadways. When evaluating pedestrian facilities, a significant distinction was made between streets with a sidewalk versus those without, asking the user different questions based on this initial response. Going beyond the physical attributes of streets and intersections, the tool also included a "social safety" component. The presumption was that the perception that a street is not "safe and comfortable" for walking may be a response to physical barriers or design elements, but it could also be because of threatening or intimidating social behavior and activity. Furthermore, rundown properties, vacant lots, and dark hiding places between buildings could significantly influence the perception of comfort and safety. 
The earliest versions of CSAT also included a set of "urban form" components that looked at building/house design, site design, and streetscape design. Building frontage, the presence of awnings and covered walkways, drainage, solar access, and landscaping also were of particular interest. The transit component at this stage was extremely simple and primarily asked whether there was seating and covered structures at bus and other transit stops. The bicycle environment audit made a major distinction between local streets versus arterials/collectors with different question sets based on functional class.

\subsection{MEETING OF THE MINDS}

On Dec. 17, 2007, a meeting was held in Eugene, OR, which brought together expert transportation planning and design professionals from around the country to test and evaluate the audit tool and provide feedback and recommendations. This meeting included Bill Wilkinson, executive director of the National Center for Biking and Walking (NCBW); Gary McFadden, NCBW's director of operations; Michael Ronkin, former Oregon Bicycle and Pedestrian Coordinator and national consultant; Barbara McCann, executive director of the national Complete Streets Coalition; Sheila Lyons, Oregon's current Bicycle and Pedestrian Coordinator; David Roth, transportation planner with the City of Eugene; and Nico Larco, architect and urban design expert. Participants provided detailed comments and priority ratings for all of the questions included in the tool at that point (see Figure 1 for a copy of one page of the feedback form the group used).

General recommendations from this meeting included: 1) refining land-use categories, 2) replacing roadway functional class with an alternative classification system, 3) omitting the tool's "social safety" component, 4) separating questions based on mode, and 5) omitting the "urban form" component but incorporating certain key questions into other parts of the tool. More importantly, this group of national experts, initially skeptical that a single tool could be used to assess complete-streets concepts, enthusiastically embraced the technology's potential for such assessments across the nation. 
Figure 1: Sample evaluation page of the Complete Streets Assessment Tool

\section{Complete Streets Assessment Tool}

Tool Evaluation

Associate Professor: Marc Schlossberg

Planning, Public Policy and Management (PPPM)

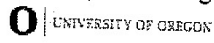

Instructions: For each of the screens identified below, use the table to evaluate the importance of each question. At a minimum, please use the rating scale to indicate how important it is to keep the particular question:
Very important
1
2
3
Neutral
6
7
8 Not important

When appropriate, please also provide comments or explanations. Space is provided at the end of the survey for general comments or concerns about the tool.

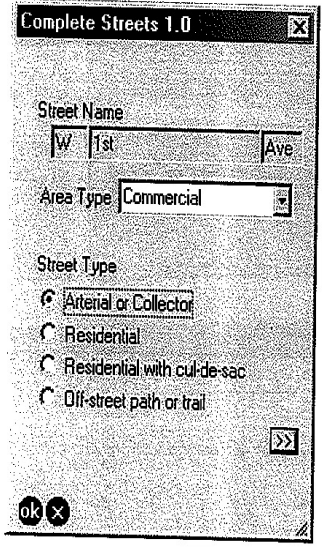

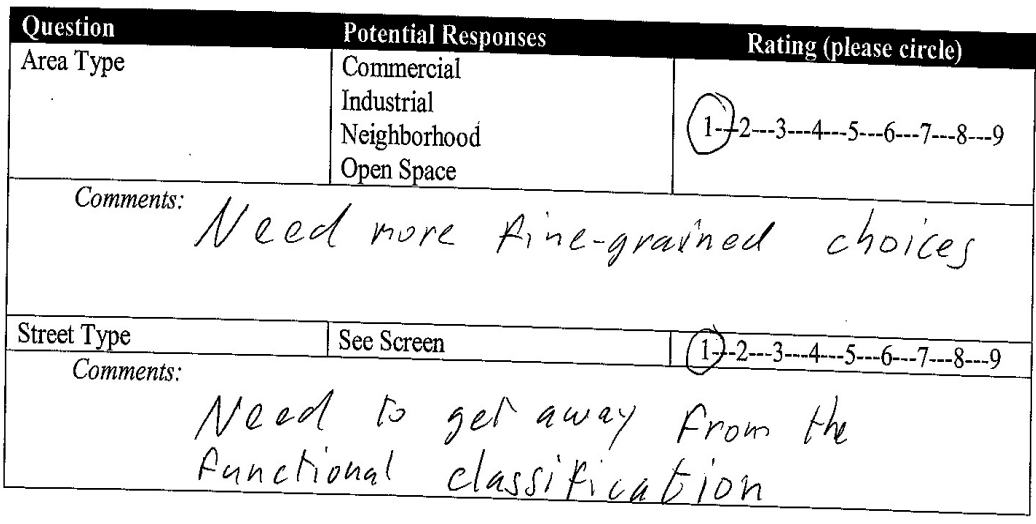

Page I 


\subsection{PERCEPTION, OBJECTIVE MEASURE, AND EVALUATION TOOL CONCEPT}

In response to the input gathered during the December 2007 meeting, the complete-streets tool was revised in various ways. Many, although not all, of the recommended changes were implemented and resulted in a new conceptual organization of the tool. Rather than starting with objective measures that lead to an "informed" subjective evaluation, people's initial perception of the safety and comfort of the street was the first consideration. This was based on the belief that most people do not conduct a detailed analysis of streets and intersections before choosing their mode or route of travel, but follow an intuitive, gut-level feeling of the place.

After capturing this initial subjective perception, the tool focused on objective descriptive attributes that should explain much of the reason behind a positive or negative subjective evaluation. For instance, if the user indicated that a street was very poor for cycling, the objective data showing that there is no bike lane on a fast and narrow, high-volume roadway provides an objective basis for that subjective evaluation.

Finally, the tool included a binary (yes/no) evaluation for each mode in terms of whether the road was adequate for a particular mode of travel. This component was intended to achieve two goals: 1) to force the user to highlight only those street segments which fundamentally fail to accommodate pedestrians, cyclists or transit users, and 2) to more easily produce quantitative, multimodal evaluations of each street segment describing which are "complete streets" and which are not. Figure 2 illustrates the basic schema of questions within the CSAT tool (there are many more pages of objective questions then displayed in this figure, however). 
Figure 2: Basic Question Schema for CSAT

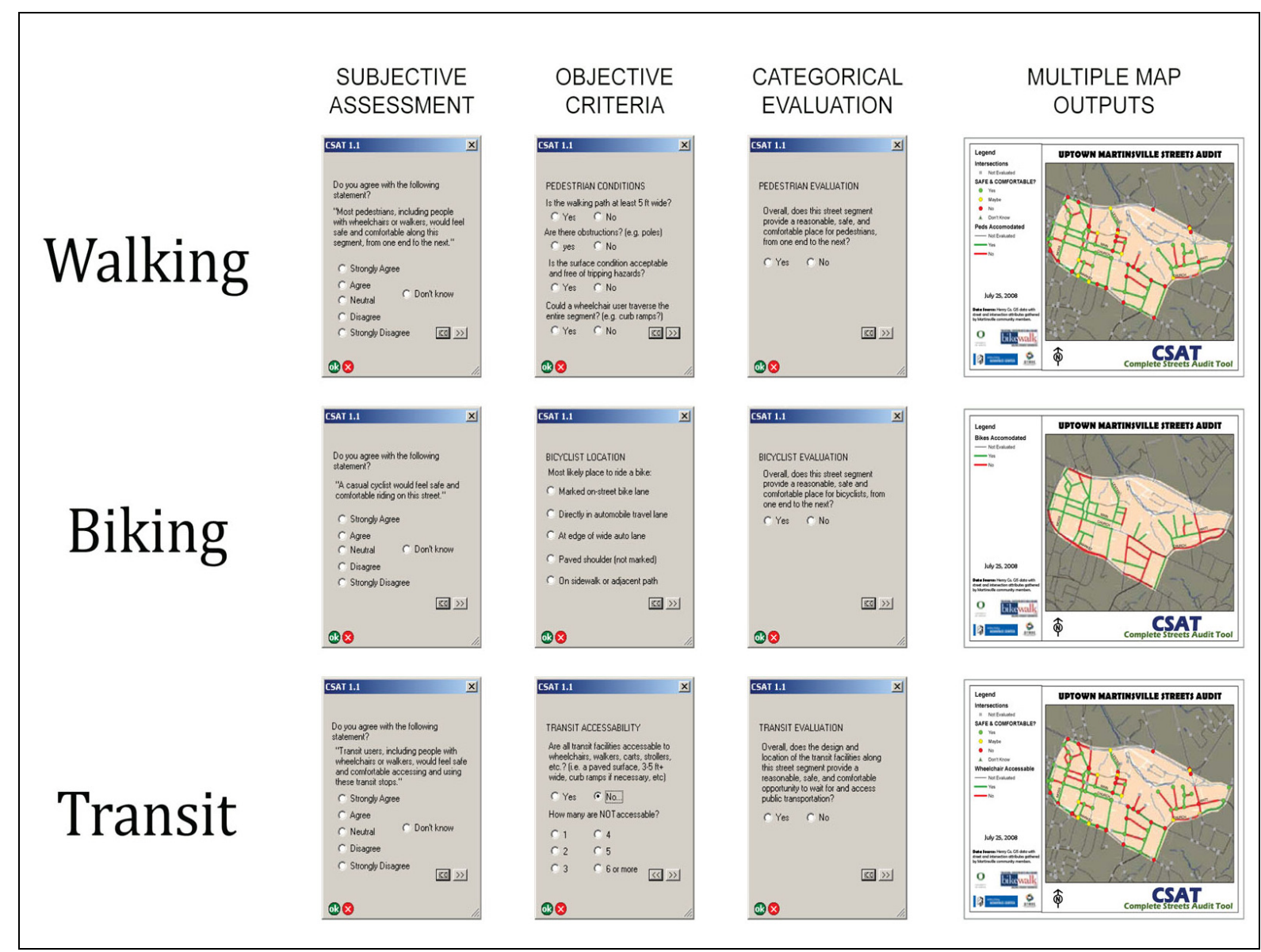

In the audit tool intersections are evaluated separately from street segments, and the focus on each is to identify barriers to use rather than highlight positive aspects of the existing environment. The guiding theory behind this approach derives from the following three-step process for getting more people to walk to a destination:

1. There needs to be a destination within walking distance before a decision to walk can be made.

2. There must be an actual path by which a pedestrian can use to get there.

3. That path cannot be horrible.

Many existing assessment tools try to identify what makes a walking environment good with the assumption that if we can know those exact elements and design other places like them more people will walk. An inverse approach assumes that one will walk to a desired destination if it is within walking distance and then only if the route to get there isn't a barrier. Pedestrian (or biking) environments do not need to be great to be acceptable and to be used, but as soon as they repel someone they are the same as not existing at all. 


\subsection{PUBLIC AND PARTICIPATION IN GIS ASSESSMENTS}

These tools have been designed with public participation GIS (PPGIS) notions in mind. PPGIS is a concept that emphasizes public access to GIS data in order to facilitate better public decision making, although rarely are the terms "public" or "participation" defined. In the case of the CSAT tools, the public refers to a general citizenry with no pre-existing knowledge either about GIS or active transportation, although participants often have some type of vested interest in active transportation (i.e., they want their children to be able to walk to school).

The nature of participation for this work is to have the public collect built environment data, view the data in map form, discuss their experiences and observations in a focused way, and then use the experience and data to advocate for infrastructure and policy changes that support active transportation. Figure 3 shows some of the participants engaged in this public workshop and data-gathering environment.

With this type of public and participation in mind, it is explicitly important to emphasize both the product and process of the data collection, as well as objective and subjective variables. Some have argued that general citizens cannot collect built environment data consistently and that subjective questions are meaningless in auditing the built environment. With a PPGIS framework in mind, we have argued for the opposite position: The best way to collect this type of data is by citizens with a vested interest and based on their individual perceptions. Because these tools are embedded in a community-workshop environment, differences of opinion about good and bad active transportation environments actually lead to community discussions around what types of values and standards should guide the improvement of the local infrastructure. This type of engagement can lead to better prioritization of improvements by cities and more sustainable investment from the local citizenry. 
Figure 3: Participants in a Complete Streets Assessment Workshop

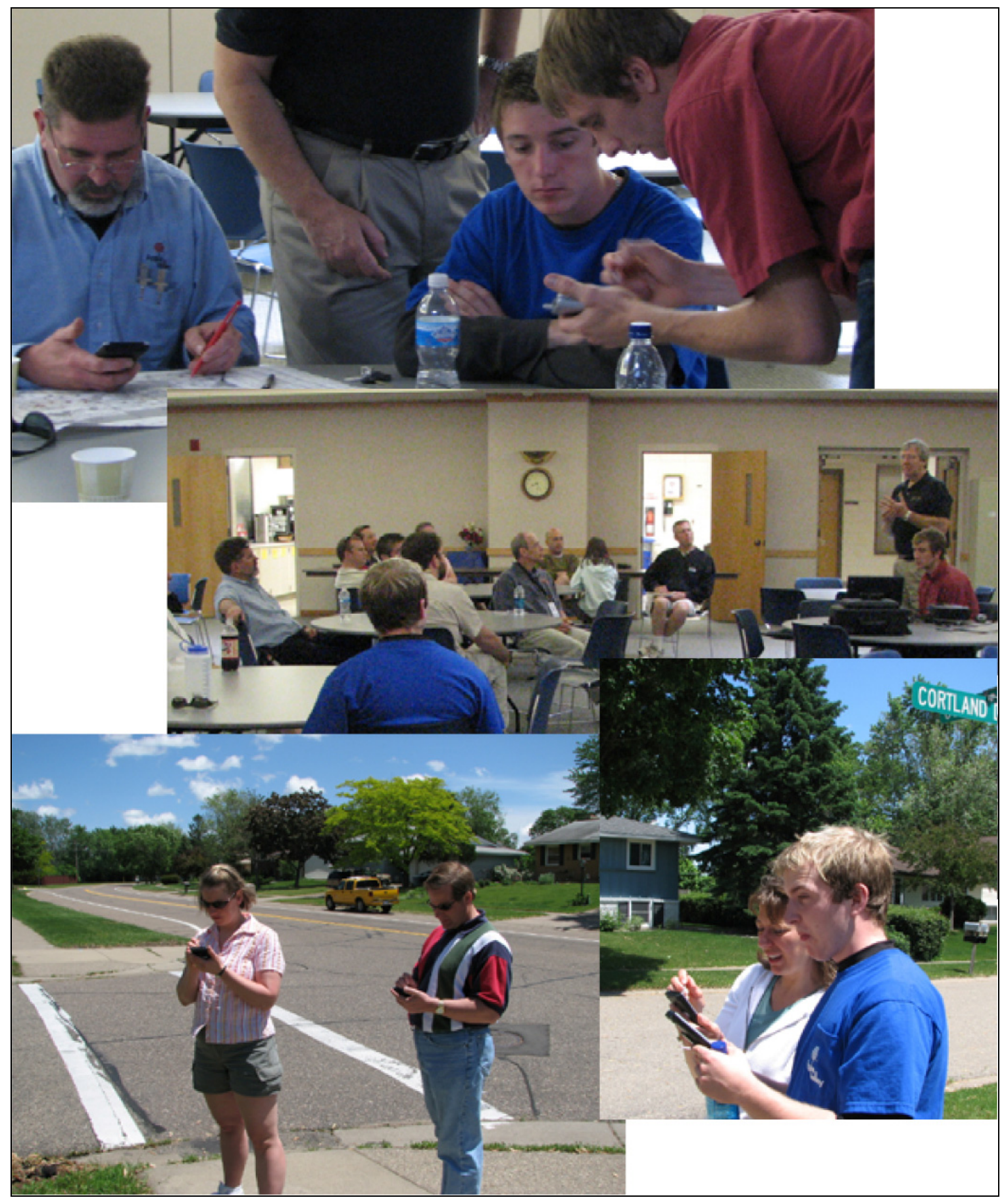




\subsection{HISTORY OF PILOT AUDITS TO DATE}

CSAT pilot audits were set up during 2008 and 2009 by staff at NCBW, which has offered workshops and trainings across the U.S. for many years. (NCBW helped set up workshops for the SEAT tool development in previous years as well.) The experience and outcomes of the pilot audits varied based on the character of the study area and the local workshop participants. Pilot studies were conducted in Silver Spring, MD., Apple Valley, MN., and Martinsville, VA. The experiences from each of these workshops and active transportation audits are below.

\subsubsection{Silver Spring, MD}

LOCAL CLIENT: William Smith and Montgomery Sideways, a small local pedestrian advocacy organization.

STUDY AREA: Silver Spring is an unincorporated urban area of around 77,000 people, located at the northern edge of the Washington, D.C., metro area. The area is characterized by aging infrastructure, many transportation and land-use retrofits, and automobile-dominated streets. Significant attempts have been made to revitalize the downtown, including a pedestrian mall and plaza-oriented shopping districts. The CSAT study area focused on the downtown, but included a good mix of arterials/collectors and local streets in commercial and residential areas.

NARRATIVE: The Silver Spring audit was the first major pilot of the CSAT. Smith, our local contact, began advocating for increased walkability in Silver Spring in 1999 when he organized Montgomery County's first walk-to-school day. The workshop was attended by neighborhood residents, seasoned pedestrian advocates, and design and planning professionals. Barbara McCann, executive director of the national Complete Streets Coalition, participated in the workshop to provide us with feedback and consider how the tool might be used as part of the national complete-streets movement. This workshop was extremely successful from the perspective of fine-tuning the audit tool, collecting data that was valuable to the local community, and helping catalyze local citizens and public agency staff around walkability issues.

When Smith contracted us to do a streets/intersections walkability audit in Silver Spring in June 2008, one of his hopes was that a successful citizen-based assessment of local streets and intersections would inspire Montgomery County Department of Transportation (MCDOT) staff to develop their own walkability audit program. Smith also wanted to give them a snapshot of the state of pedestrian and transit infrastructure in local neighborhoods. According to Smith, "The questions raised by the CSAT project in Silver Spring began a whole new line of discussions that have lead to significant changes in the county's approach to pedestrian infrastructure." He also told us that the CSAT workshop was perfect in that it provided local citizens with a way to engage in a meaningful project without a long-term commitment.

The top leaders at MCDOT have scrutinized data collected during the CSAT audit in Silver Spring. Map data related to the walkability of specific intersections and streets is regularly compared to the post-audit crash history in the area to emphasize the validity of the data and the urgency of implementing changes. After independent verification of community-gathered data, MCDOT staff have corrected a number of pedestrian infrastructure problems, developed action 
plans, and made the decision to fund and staff their own mobile GIS-based walkability/bikability audit program based on the CSAT model.

Montgomery County staff contacted us in October 2008 (two months after the citizen-based audit) to request guidance and technical assistance on setting up their own program. We have guided them through the process of setting up hardware, software and licensing, and provided them with the CSAT digital files and supporting documents.

Montgomery County staff has experienced a number of barriers over the past year in implementing their audit program. These include funding constraints, internal approval processes, and obtaining the necessary hardware and software licenses necessary to run the latest version of ArcPad software. In addition, even with professional GIS staff, the county office has required significant technical support in using ArcPad as a walkability/bikability audit tool. Most of these difficulties have now been resolved and the office will soon launch its program. However, the difficulties they experienced suggest that a different platform (non-ArcPad), which is more streamlined, has a lower cost and requires less technical expertise, may have greater success and the capacity for wider distribution and impact.

\subsubsection{Apple Valley, $M N$}

LOCAL CLIENT: Apple Valley and Dakota County staff, including planners, engineers and support staff, many of whom were sent to the workshop by their supervisors.

STUDY AREA: Suburban area south of the Minneapolis/St. Paul area, with two major highspeed arterials lined by strip malls and big-box stores, and a homogenous suburban residential neighborhood. There were no bus or transit providers serving the area.

NARRATIVE: The June 2008 complete-streets audit in Apple Valley was organized in conjunction with other projects related to physical activity, community health and livability, which were funded by Blue Cross-Blue Shield grants. One of the requirements of this funding was to conduct various built environment evaluations in the community. Workshop participants consisted primarily of engineering, transportation and land-use planning staff and GIS technicians from the local and county agencies who were sent to the workshop by their supervisors. There was one lay citizen in attendance.

The audit tool produced a solid spatial data set of the street and intersection network. The winding network of local residential streets was determined to be generally acceptable for walking, although the three-foot-wide sidewalks did not allow two or more people to walk side by side or mass each other. Moreover, the lack of curb ramps and poor alignment at intersections failed to support pedestrians with mobility impairments or wheelchairs (this led us to develop a separate Accessibility Audit Tool (AAT) to focus on street infrastructure issues related to the Americans with Disabilities Act). Nearly every segment and intersection along the two major arterial roads was less than adequate for walking and completely unacceptable for biking.

While the workshop was successful as a data collection and mapping exercise, the goal of catalyzing community change was not reached in any meaningful way. During the discussions 
and walkability/bikability design trainings before and after the field audit, it became clear that the participating staff had little desire to change conditions in the area. Not only this, but they shared their plans for widening the major north-south arterial, excluding street trees and pedestrian buffers, and increasing the speed limit from 45 to 55 miles per hour. The staff believed there was a need to increase automobile mobility rather than multimodal accessibility on this street. The arterials were already a major barrier for pedestrians and cyclists moving between residential land use and schools to the west, and a supermarket and other shopping areas to the north and east.

Reinforcing this preconceived plan for the area, the local organizers chose a residential area that was generally acceptable, but the study area excluded adjacent residential areas that made few or no provision for walking and biking at all. The choice of study area and conclusions would have been different, we believe, if the workshop were attended primarily by citizens and others with a more vested interest in active transportation.

\subsubsection{Martinsville, $V A$}

LOCAL CLIENT: Jeanie Frisco, executive director of Activate Martinsville - Henry County (AMHC), with a diverse team of local supporters and allies.

STUDY AREA: Mix of arterial/collector, downtown commercial, and local roads and arterials. Includes an historic "uptown" area which the community is devoting significant resources to revitalize.

NARRATIVE: The City of Martinsville, located in south-central VA near the North Carolina boarder, has experienced a decreasing population and loss of vitality in its central, old-town area. The three-year Activate Martinsville - Henry County (AMHC) imitative was launched in June 2007, with a $\$ 1.5$ million grant from the Harvest Foundation, to "improve the quality of life in the county by increasing active living and active tourism." To support its goals, Jeanie Frisco contacted the NCBW to conduct a mobile-GIS workshop audit of their streets and intersections. Workshop participants included affluent and influential community members focused on leisure/recreational bicycle routes and less affluent participants concerned with the livability of Martinsville from the perspective of the poor and disabled who may not own vehicles and must cross automobile-oriented arterials and intersections.

Both the data collection efforts and participatory process were highly successful. We found that while a number of streets and intersections in the city and county were indeed barriers to walking and biking, many of the streets in the old-town area were already optimally designed to support healthy pedestrian-oriented land use. One of the major barriers seemed to be the attitude of local residents, including the workshop organizers, but the workshop format allowed for those biases to be made public and for a community discussion to recognize and begin to move beyond such preconceived and seemingly hardened positions. 


\subsubsection{Communities and Schools Together (CAST)}

Because of the success of these citizen-based assessments, the CSAT tool has been adopted for a major national research project on childhood obesity.

The Community and Schools Together (CAST) project is a five-year, community-based research project focused on childhood obesity that is funded by a major grant from the National Institutes of Health (NIH). The project looks at multiple factors influencing childhood obesity, including access to nutritional food, general nutritional education, and different aspects of physical activity. Part of the physical activity research includes a built environment assessment to be conducted by local community citizens so they can both develop a comprehensive built environment database and become local experts about good and bad urban design.

The focus area of this project is the Bethel Neighborhood in Northwest Eugene. Bethel is adjacent to industrial lands, experiences a higher crime rate, and is overrepresented by lowincome and minority populations. Due to its basis in community-based research, the CAST project is as much concerned about research findings as it is about community interventions and behavior change. The CSAT tool fits perfectly within this paradigm.

The CAST project has just completed its first year and the first three of seven community-based active transportation assessments have been conducted (see Figure 4). The use of the assessment tools and transferring the technology to the community has taken on a different format within this CAST project than the other community workshops, which will be discussed later in this report. That said, the adoption of this tool by a national NIH research project is good evidence of its potential to help catalyze and organize communities to help improve the active transportation environment. 
Figure 4: CAST Project, Bethel Neighborhood, Eugene, OR.

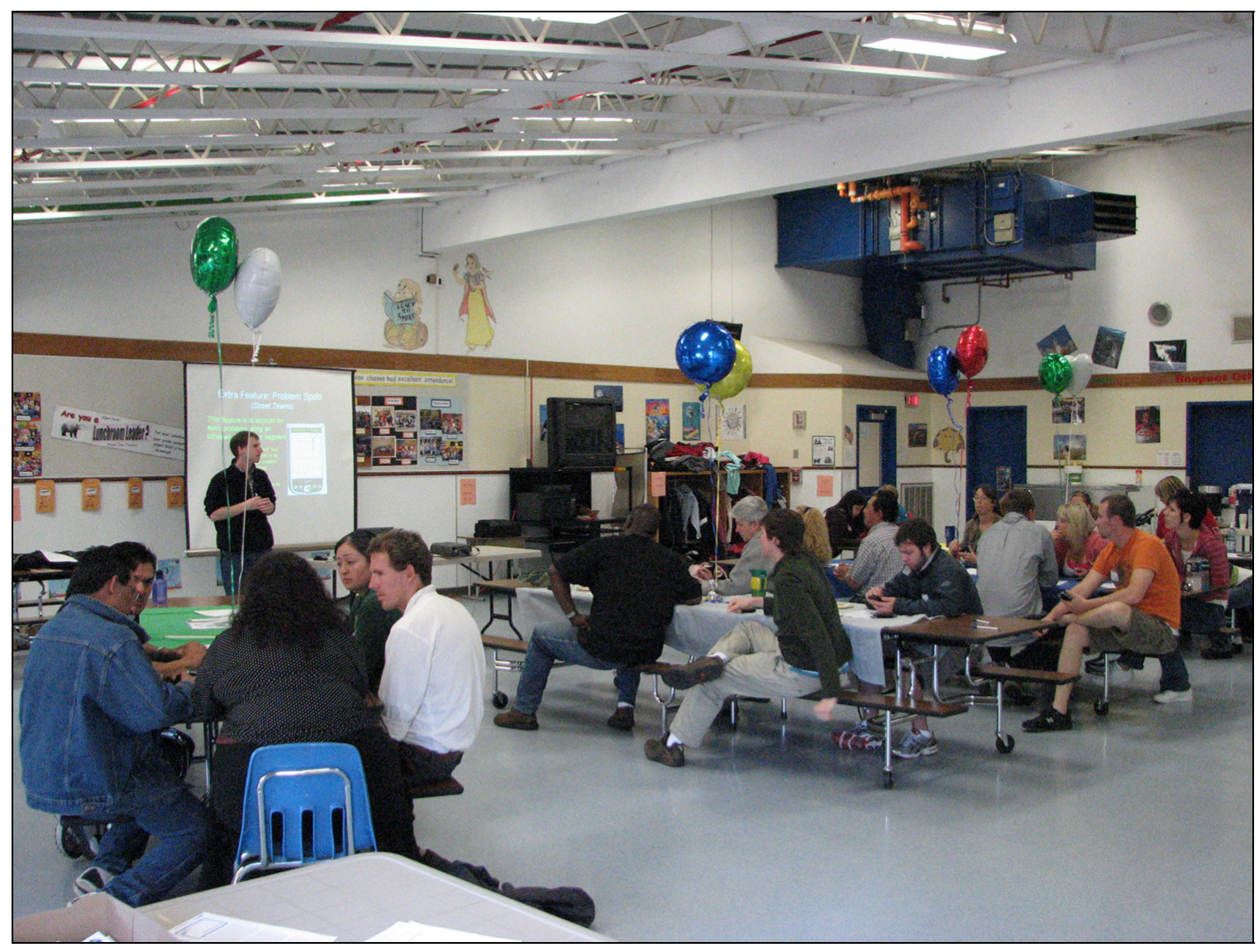




\subsection{COST OF CONDUCTING AUDITS}

While each of these projects showed the participatory mapping tools to be useful in assessing the transportation environment and catalyzing community interest, education and action, these workshops also demonstrated the enormous cost required for a community to adequately utilize such tools. In each of the cases, much of the cost was hidden because of project subsidizes made available through the OTREC project grant, including financial support from the main project partner, the Active Living Resource Center. But to transition these tools from the university laboratory to communities across the country while making those communities responsible for the full cost may be prohibitive. Below are some of the specific elements that carry a cost for communities if they were responsible for the full financial burden.

Hardware requirements:

There are two main hardware requirements if using these tools as developed:

Personal Digital Assistants (PDA): Community members use these PDAs to collect the field data, workshops typically utilize 20-30 PDAs, although this is dependent on the number of citizen participants, and each PDA costs between $\$ 300-\$ 600$.

Laptop to run GIS software: A key component of these audit tools is the immediate community dialogue they foster and, thus, it is important to be present at the workshops with technology to synthesize disparate data into comprehensive maps for display, dialogue, and discussion on-site. The data also requires some pre- and post-processing with GIS software and the hardware to run this software cannot really be provided by most communities.

Community Cost: $\$ 10,000$

Software requirements:

There are two critical pieces of software to make these tools work, which require expensive licensing, and which most communities have no or limited access to:

ArcPad and ArcPad Application Builder: These two pieces of software are what make the PDAs easy to use and are directly connected to larger GIS databases. Community Cost: $\$ 2,000$.

ArcGIS: This is the primary GIS software used to process data, produce maps, and conduct various spatial analyses.

Community Cost: $\$ 15,000$

Obtaining base GIS data: 
The past workshops have run mostly on free base GIS data to keep costs low. In some cases, communities may wish to have access to fee-based data.

\section{Community Cost: $\$ 0$}

\section{Customization of the tool at community request:}

The tools presented here have been modified over time as they were developed, but at some point they can be considered finalized versions ready for broader distribution. If a community then wants to customize a tool by adding or subtracting questions, that customization must be done by someone trained in the software mentioned above, requiring a customization cost.

Community Cost: $\$ 3,000-\$ 15,000$

$\underline{\text { Site travel: }}$

Currently, the technology is such that workshops have been led by facilitators trained in active transportation issues, public facilitation, and participatory GIS tools. To conduct a workshop, this leadership team must travel with the tools to the site, which includes normal travel costs such as plane, hotel, food, and consultant time. A single, six-hour workshop, however, normally requires at least three days of travel because there is pre-site analysis and post-workshop follow up that needs to be conducted. Additionally, two or three workshop facilitators are required so that citizens can be engaged in a discussion while data is synthesized and publicly mapped.

Community Cost: $\$ 5,000$ - $\$ 10,000$.

\section{Correspondence with "client":}

There is often a significant amount of pre-workshop planning, post-workshop data processing, map preparation, and report generation that requires significant time and development with the community, or "client."

Community Cost: $\$ 3,000-\$ 15,000$

Under the model of distribution used thus far, one where tools and staff time originate at the University of Oregon and travel/workshop facilitation are subsidized through project partners, the costs to the community if this were a straight fee-for-service arrangement would range from $\$ 38,000$ to $\$ 52,000$ for a single, six-hour workshop. If a community were to have multiple workshops during a single period of time (3-5 days), there would be some efficiencies of scale, but the investment is still quite significant. We feel this model is cost-prohibitive as a straight fee-for-service and the following section will delineate several alternative approaches for tool distribution and use. 


\subsection{DISTRIBUTION/DISSEMINATION MODELS}

Our experience of running citizen-based active transportation mapping workshops across the country has been quite positive, as evidenced by the overview and highlights above. It is also clear that the cost of any individual workshop is quite high and the geographical coverage of a short-term intensive data collection effort is limited. The costs of the cases highlighted above were all subsidized in one way or another - either through third-party payment of the costs or through undercharging the hourly costs of the technical assistance. These subsidies were offered in order to test the tools and observe their use in practice, but are not necessarily sustainable as a funding model for additional communities.

That said, given the high value of both collecting fine-scaled, spatially-oriented, active transportation data and engaging citizens in the process may be worthwhile in the long run as communities work toward increasing the livability of their areas by improving transportation choice and supporting active transportation options. Below are five options for financially supporting the more intensive, workshop-based approach to community data collection.

\subsection{OPTION \#1: GRANT FUNDED}

The community workshops thus far have been supported under a grant-funded model where a third-party funder facilitated the match between the University of Oregon participatory mapping team and an amenable community. The NCBW, via its affiliation with the Active Living Resource Center and the Robert Wood Johnson Foundation, provided essentially a full subsidy to any community that wanted to utilize the CS, SRTS, or ADA assessment tools. The local community needed to commit staff time and organizational resources to solicit community volunteers, secure a date and location of the transportation audit, and supervise other workshop logistics. Local communities also needed to demonstrate a true desire to investigate their active transportation environment, including having some ability to act on the experience and results of the workshop once the mapping assessment concluded.

This matchmaking via a grant-funded third party proved a good model because it separated the technical work at the University of Oregon from the logistical work of community organizing facilitated by NCBW. In addition, expertise from NCBW staff was part of the mix so local communities received technical mapping expertise as well as substantive expertise in active transportation from both the University of Oregon and NCBW. Travel, lodging and workshop costs were all provided by grant funds through a combination of OTREC and NCBW, leaving only minimal costs (mostly time) to the local communities. Clearly, from the community perspective, this model is very attractive as there are minimal financial costs and there is a substantive amount of external expertise that becomes available for staff and citizen engagement. 
The obvious limitation of this model is that it relies on third-party grant funding, and such funding may be limited in time and subject to changing priorities. Such was the case for this project because NCBW's support ended for this particular type of work.

$\underline{\text { Pro: }}$ It provides a significant subsidy (financial and expertise) to the local community, and separates some of the community work between technical assistance and community organizing assistance.

Con: It is an expensive model that depends on grant funder prioritizing work.

\subsection{OPTION \#2: PUBLIC AGENCIES/LOCAL GOVERNMENT}

A different financing approach could be to have local municipalities take on the financial support of the project rather than a grant funder. The rationale in this approach is that the public sector would be supporting what is essentially a citizen engagement process aimed at making the transportation system more responsive and livable for the community. Local governments already support community engagement efforts around a variety of topics, but especially around various livability and transportation aspects. As cities try to figure out how to meet new carbonfootprint goals, engaging citizens around active transportation and urban form will increasingly be important as new policies and programs are developed. Thus, a local government may see an investment in these workshops and tools as a wise strategy that actually falls within the normal course of activities in which they engage.

Pro: The citizen engagement model of these active transportation assessment tools clearly is consistent with the public mission of local government and may actually help local government better achieve its goals. Also, public agencies often have technically trained staff and the financial and personnel resources necessary to conduct this type of audit.

Con: The cost for the workshops may be above and beyond existing programmatic funding levels and be seen as an extra and unaffordable expense. Also, these agencies are generally already involved in data collection activities and may be focused on a limited set of engineering-focused features of the built environment. Staff may not appreciate the community-involvement component that is a key attribute of the tools. Even trained GIS staff may have difficulty obtaining the appropriate licenses and performing tasks associated with preparing for a mobileGIS workshop.

\subsection{OPTION \#3: LOCAL ADVOCACY GROUPS}

In this model, a local advocacy group would be the leader and funder, probably through external grant support. Local advocacy groups often fill in the gaps where local government cannot or do not want to provide resources. Many communities have advocacy groups around healthy lifestyles, environmental issues, neighborhood preservation, etc., and it may be that any one of these groups are interested in advancing their agenda through an organized and nationally 
credible tool that helps citizens assess the quality of their built environment in terms of active transportation.

Pro: This option involves highly focused and committed groups of people who have an interest in recognizing barriers to walking and biking. This user group is relatively easy to train in the concepts of walkability and bikability and already is more aware of their local infrastructure's condition. Funding is secured by a third party. An additional key benefit is that advocacy organizations are positioned to take the results of the data and the catalyzing nature of the citizen engagement and translate that into tangible actions to bring about change at the local level.

Con: Many local advocacy organizations lack the fundraising capacity to fully pay for these tools as they exist at this time. These organizations also tend to be volunteer-based and cannot afford the cost of this type of workshop.

\subsection{OPTION \#4: NATIONAL ISSUE GROUPS}

Rather than local advocacy groups being responsible or being the primary catalyst for organizing and funding the built environment assessments, national advocacy groups could provide such leadership and then work with local partners on the specific workshops. This is the model that has been employed thus far, with the NCBW, through its management of the Active Living Resource Center and in partnership with OTREC, funding the tool development and community workshops across the country.

There are several national organizations that would be logical partners in helping support continued tool development and deployment, including the Complete Streets Coalition, Rails to Trails, the Congress for New Urbanism, and other groups working at the intersection of urban design, active transportation, and community livability. Certain organizations such as the Complete Streets Coalition may be particularly good sustainable partners with specific tools developed, such as the CSAT, the nation's first participatory GIS tool for assessing various elements associated with the idea of "complete streets." There may be similar groups that would be particularly interested in "adopting" tools for the Americans with Disabilities Act, Safe Routes to School, or tools focused on biking.

Pro: A national organization has greater financial resources to utilize these tools, greater reach to think both nationally and about a community at a time, and is in a position of translating workshop use into policy change at a variety of political scales.

Con: National advocacy organizations are dependent on grants or member fees, which in part dictate the priorities and directions for the organization. Thus, funding can be unstable over an initial project period (e.g., NCBW provided three years of support). Also, national advocacy organizations may be looking for a good deal of interpretation and policy recommendations as a product of this type of street assessment rather than just facilitating local education and capacity building around an issue. 


\subsection{OPTION \#5: STATE/NATIONAL GOVERNMENT PROGRAMS}

At the state or national scale, there may be programs that would want to "adopt" these tools and distribute them to local partners through some internal mechanism. One example could be the Safe Routes to School Program, supported at the federal level and carried out in every state in the country. This program is responsible for increasing the numbers of children who walk or bike to school across the country and funds are distributed through local grant applications to a state entity.

It may be that the federal oversight of this program, or individual states, could require that every local school applying for funds to improve their walking/biking environment must first conduct a participatory GIS, complete-street assessment. Communities that are organized enough to submit funding applications could receive funds through the state/national office to hire the mapping tools and process, thereby increasing their local understanding and capacity to implement and sustain the changes they seek.

Pro: A national program already exists with mechanisms to distribute funds to each state and to require local communities to carry out certain tasks before applying for funds. A mapping assessment could easily be integrated into this structure, with funds coming from the national or state government to help local community assessments. A national approach could fund the operation as a whole, increase the reach and distribution of the tools, and decrease the costs of workshops based on an ad hoc model.

Con: Mandating that communities engage in another requirement before receiving funds may be met with some resistance. There would need to be some sort of incentive, such as an advantage in the application and selection process, to justify the cost and time associated with conducting this type of extensive audit.

\subsection{OPTION \#6: "TRAIN THE TRAINER" MODEL}

Each of the options above present a model that continues the existing workshop format where streets are assessed through a collective contribution of local citizens facilitated by an expert in participatory GIS and these tools specifically. A general limitation of this approach is that the geography that can be covered through a single workshop is fairly limited to the area immediately surrounding the workshop location and dependent on the number of engaged citizens and the time allotment they give to the process.

One modification of this citizen engagement model that could reduce costs could be to "train the trainer," which implies that a local community member, organizational staff person, or local public official becomes trained as a participatory GIS leader. In this model, the outside experts come in and lead the workshops as before, but a local person becomes trained in the process that can lead subsequent community workshops to increase the area that can be assessed. These subsequent workshops would not require travel or facilitation costs. 
The "train the trainer" model was adopted in the CAST project with good success. The project itself is five years in length covering an entire section of a city (Bethel in Eugene, OR). So, the circumstances of the project led more easily to a longer-term approach of building local capacity to carry out community-based transportation assessments. Initial mapping workshops were led by university experts in similar fashion to other workshops across the county over the last few years. The basic workshop included an introduction to obesity, active transportation, and urban design, followed by a hands-on training of mobile GIS and a few hours of data collection. It concluded with a facilitated discussion of the audit process. The initial workshops were approximately six hours long.

Part of the larger CAST project was to recruit a Parent Council, a body of individuals from the community who would take some ownership of all the elements of the CAST project (built environment assessments, school nutrition interventions, food desert(??) analyses, and general community education) and work to make community change. The first tangible work of the Parent Council was on the active transportation audits, although participation in the audits was extended beyond just the Parent Council members (see Figure 5 for a flyer describing the assessment process to garner interest and recruit Parent Council members). After the initial two workshops, it became clear that there would be participants who would continue to participate in the five to eight subsequent assessment days, and we felt this would be a good opportunity to test the "train the trainer" model. 
Figure 5: CAST Project Flyer Advertising Complete Street Workshop

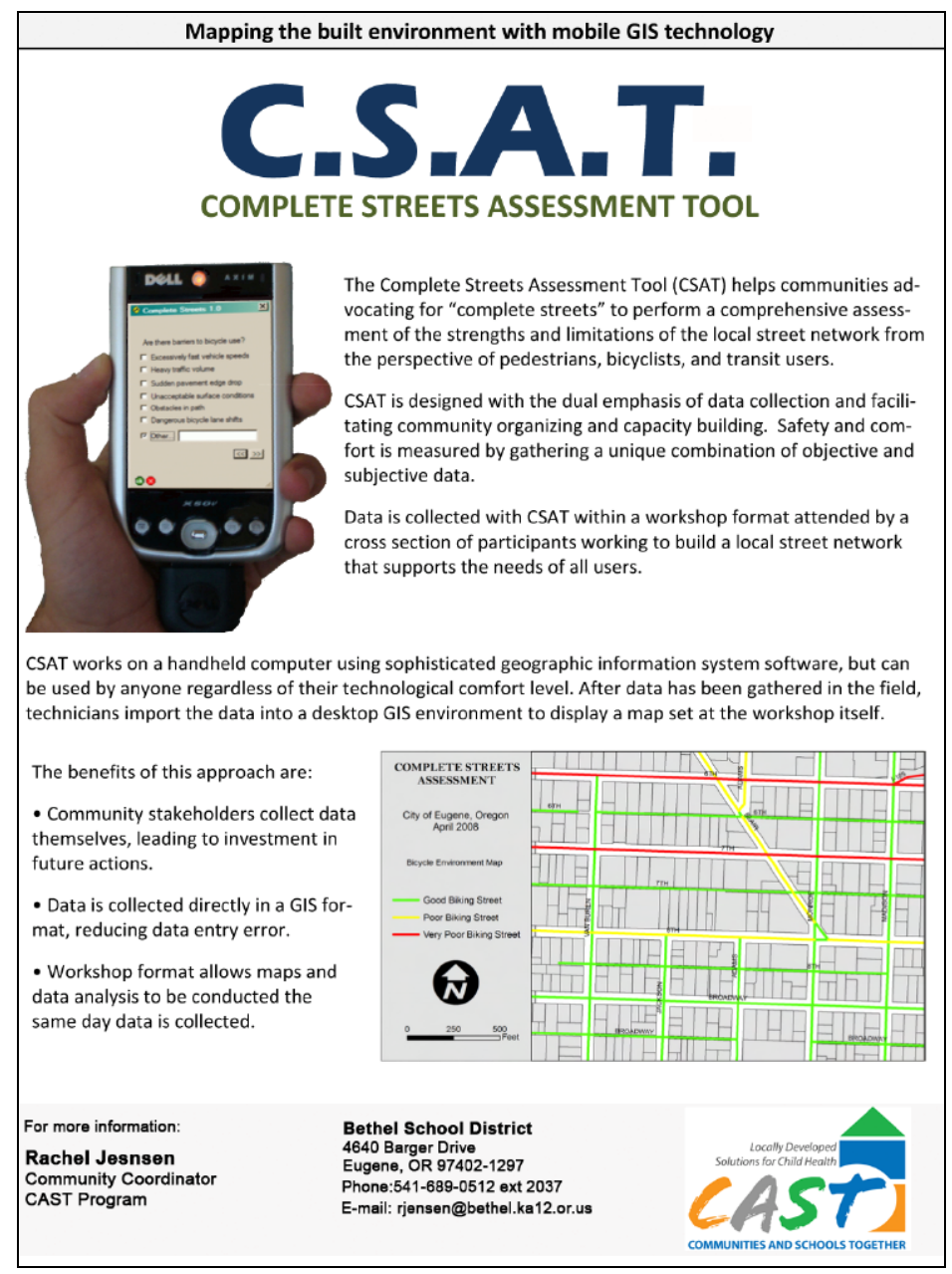

The workshops were reduced from six hours to three by virtually eliminating the hands-on tool training. Participants at the subsequent workshops were given an accelerated introduction to issues of urban design and only a brief reminder of how the assessment tools work. The presentation was given two more times by the university project team, but was then handed off to the CAST project manager who, while new to the details of urban design and active transportation, became sufficiently trained in the basics through participation in the workshops to date.

In terms of data collection, new community participants were paired with an experienced member (someone who participated in a previous audit) to go into the field and collect data. The experienced person would conduct the computer training on the fly, in addition to providing guidance on how to look at the built environment to appropriately evaluate different elements relevant to active transportation. After completing the first two workshops in this format, it is clear that information can be conveyed to new participants in this way. In addition, transferring the educational responsibility to more experienced community members increases their level of responsibility and ownership of the process, and thus will likely lead to greater continued involvement as the project transitions from data collection to community and policy change. 
Pro: There are two main advantages of this approach. First, the mapable area increases as multiple workshops can be conducted through local leadership. The incremental cost of each workshop is extremely minimal in this model (basically the cost of food for workshop participants) as the local trainer becomes responsible for leading the community mapping process. Second, this approach transfers built environment assessment expertise to the local community, a significant technology transfer and potential contributor to longer-term sustainable success in the overall effort to improve the active transportation environment.

Con: There are several aspects of this approach that change the workshop dynamic as has been developed over the course of this OTREC project. The main difference is that on-site GIS analysis is eliminated as it is likely that the local trainer could help guide citizens through data collection and discussions, but not data integration and real-time mapping. In addition, this model requires that the PDAs be left in the community for some extended time period (assuming that the community cannot or will not buy its own fleet of 20-30 PDAs), thereby increasing some liability concerns and also removing the PDAs from availability at other community locations. 


\subsection{CHANGING THE MODEL: FROM CENTRALIZED TO DECENTRALIZED}

A large component of the cost and the primary limitation for more widespread distribution of these community assessment tools may be that the community-based built environment audits have followed a centralized approach where trained GIS experts using a robust GIS system facilitated a community process of collecting and analyzing attributes of the local active transportation environment. With the rapid growth and availability of "smart phones" that give users Web access, navigation maps, and computing capacity within a personal mobile phone, along with the increased use of GPS location-based services on such phones, it seems that there may be an opportunity to decentralize the built environment assessments to individual citizens using their own personal mobile phones. Moving in this direction would be a fundamental shift from a collective approach covering a small geographic area to an individual-based data collection approach, but with the potential of much greater geographic coverage.

Exploring these new technologies with the constant project goal of engaging the citizenry in observing, evaluating, and acting to change their active transportation environment seems to be worth pursuing. The cost advantages are clear since the technology used would already be in the possession of many citizens - the mobile phone - and use of online maps and navigation devices have become widespread, so the technological barrier to entry is low. That said, moving to a mobile phone-based mapping technology would represent a fundamentally different approach in many aspects. This section of the report discusses those differences.

The overall mapping process can be delineated into nine primary attributes (see Table ). It is important to keep in mind that this work is part of a public participation process, so while there is an even more centralized model of expert-based data collection, this project seeks to maximize citizen engagement and involvement in the evaluation and mapping of their own local built environment.

Table 1: Parameters of Built Environment Assessment Models

\begin{tabular}{|l|l|l|}
\hline & $\begin{array}{l}\text { Community-based Mobile } \\
\text { GIS Tool (Existing Model) }\end{array}$ & $\begin{array}{l}\text { Mobile Phone Mapping } \\
\text { Tool (Potential Model) } \\
\text { Partially Centralized } \\
\text { Partially Decentralized } \\
\text { Expertise (PCPDE): }\end{array}$ \\
\hline Space & $\begin{array}{l}\text { Cecentralized Distributed } \\
\text { Expertise (DDE): }\end{array}$ \\
\hline Time & Time-limited data collection & Not time limited \\
\hline
\end{tabular}




\begin{tabular}{|l|l|l|}
\hline Nature of Participation & Workshop focused & Lifestyle focused \\
\hline Definition of Public & $\begin{array}{l}\text { Definite survey group } \\
\text { (usually an interest group) }\end{array}$ & $\begin{array}{l}\text { Survey group may include } \\
\text { broader audience }\end{array}$ \\
\hline On-Site GIS Requirements & $\begin{array}{l}\text { GIS-licensed computer } \\
\text { required on-site }\end{array}$ & $\begin{array}{l}\text { GIS processing run from } \\
\text { off-site lab }\end{array}$ \\
\hline Community Dialog Needs & $\begin{array}{l}\text { Facilitator and GIS } \\
\text { technician required on-site }\end{array}$ & Only facilitator is required \\
\hline General Costs & $\begin{array}{l}\text { Facilitation and data } \\
\text { collection is costly }\end{array}$ & Costs are minimized \\
\hline What Gets audited & $\begin{array}{l}\text { Each street segment } \\
\text { evaluated by only one user }\end{array}$ & $\begin{array}{l}\text { Street segment evaluated } \\
\text { by more than one user }\end{array}$ \\
\hline Breadth of Evaluation & $\begin{array}{l}\text { Comprehensive street } \\
\text { survey guaranteed }\end{array}$ & $\begin{array}{l}\text { Data collection may focus } \\
\text { on certain areas }\end{array}$ \\
\hline
\end{tabular}

Space: Space refers to the geographic coverage of an assessed area. In the centralized approach, data collection is done within a relatively small geographic area surrounding a designated meeting spot. The exact area is determined by the project goals, number of participants, and time allocated to data collection. In a fully decentralized approach, data can be collected wherever one desires.

Time: In the centralized approach, the time allocated for data collection is pre-set and restricted by the workshop format. In the decentralized model, participants can collect data whenever they desire.

Nature of Participation: In the centralized model, participants actively participate in both data collection and discussion, and that participation is facilitated through an organized daylong workshop. In the decentralized model, participants also are actively engaged in collecting the data, but can do so as their individual desire and lifestyle allows. There is no discussion element inherent in this approach.

Definition of Public: In the centralized model, the public participants are to some degree preselected, although who attends the workshop often is not known until they show up. Participants are generally identified by their interest in or connection to the particular reason the mapping workshop was organized. In the decentralized model, assessments are open to anyone who can access the tool and reach a broader range of interests then workshop organizers may identify.

On-site GIS Requirements: In the centralized model, a GIS technician and capable machine must be present to collect data from individual PDAs, synthesize data, and transform it into maps for community discussion. In a decentralized approach, the technology has moved away from GISspecific and the need for any on-site technical help is eliminated. In the decentralized model, 
there is still a need for technical work, primarily in behind-the-scenes efforts in database management and Web server applications.

Community Dialog Needs: In the centralized approach, both a facilitator and GIS technician are needed to guide participants through reflection and visualize the data just collected. In the decentralized model, group discussions can be organized in an ad hoc way throughout the community, and only a facilitator (and Web access) is needed to dissect and interpret data.

General Costs: In the centralized model, especially one based on GIS, there is considerable cost. The workshop format requires technical assistance, specialized computer devices, and expensive software. In the decentralized mobile model, there are software development costs, but distribution is online, devices are existing ones owned by community members, and training can be done through the production of online training videos or just through the intuitive nature of mobile phone applications.

What Gets Audited: In the centralized workshop format, each street and intersection gets evaluated by one user to ensure full geographic coverage and efficient use of participants' time. In the mobile decentralized model, street segments and intersections can be evaluated by many different users and may provide more reliable information on community values.

Breadth of Evaluation: In the centralized model, every street and intersection within the identified study zone gets evaluated. In the decentralized approach, there may be large areas of unaudited areas since the direction for what to assess is dependent on individual, not centrally organized, decisions.

\subsection{PARTIALLY CENTRALIZED PARTIALLY DECENTRALIZED EXPERTISE (PCPDE)}

The existing model of mobile-GIS tool development and distribution follows a Partially Centralized Partially Decentralized Expertise (PCPDE) approach. In the PCPDE method, centralized knowledge and centralized data collection and facilitation activities take place.

In the centralized workshop approach, community assessors all gather at a single location for an introduction to the topic, training on the assessment tool, and discussion during the active transportation environment post-workshop. The gathering place is important, both by embedding the mapping process in the community by utilizing a local meeting space and in that the meeting space is centrally located for the day's mapping area. Participants generally walk out from the meeting space to conduct their built environment assessments, thus gathering at a central place is important for the overall process. Re-convening at the end of the audit time also reinforces the community space and provides a focal point for participants to gather and discuss their observations, experiences, and impressions of their local community. Gathering in this central location with a focus on the day's mapping activities is a critically important aspect to the workshop-based approach to built environment assessments. 
In the current model, the tool developers become the expert, on-site GIS technicians and also the workshop facilitators. Usually this team is working in communities outside their own to help guide local citizens through the data collection process and through the dialog around active transportation issues that can help move the community agenda forward. This collection of outside expertise can be thought of as a centralizing element of the work because utilization of the mapping tools require a level of expertise that is limited in availability and therefore centralized in nature.

In addition, the collection of data can be partially thought of as a centralized approach. The existing model requires that a group of community members meet at a central site (often a school, library or other community space) to receive assessment training and then the built environment assessments take place within a relatively small radius from that training site. Obtaining greater geographic coverage in data collection would require additional training at sites throughout a community. Because citizens need to come together to a single place for training and to focus on a relatively defined geographic coverage area (i.e., a $1 / 2$ mile around a school), each workshop and tool distribution has a centralized component to it.

The public involved in the PCPDE is open to wide participation, but usually is filtered somewhat by whatever group is responsible for local organization of the assessment. That organizing group would necessarily limit participation in data gathering either by existing organizational members (i.e., if an advocacy organization), through limited and defined networks (i.e., if organized by a school) or through larger but still defined interest groups (i.e., city-organized public process but advertised through active transportation-related working groups).

In sum, the PCPDE model, as developed with the suite of built environment assessment tools, engages a general citizenry in a new way in terms of both collecting data for and engaging with issues of the active transportation environment. Compared to the normal course of data generation, collection, and community engagement, this model presents a fairly radical approach to harnessing citizen "experts" to both identify strengths and deficiencies in their walking and biking environment, and helps organize and catalyze them into acting to make the environment better. This citizen investment can lead to more investment in future projects and more committed use of the active transportation environment as it is improved.

There are many benefits to this model as it combines a general citizenry with existing experts to collaborate in the development, interpretation and application of new transportation data. Training on tool use and debriefing among assessment participants are further efforts to transfer knowledge about the relationship of urban design and active transportation - knowledge that local citizens can carry forward in whatever local activities they engage in around these topics.

Moreover, collecting data and discussing it as a group also can create citizen coalitions that may work together more effectively to push for changes at the local level, which any one concerned individual may be less likely to accomplish by him/herself. This collective experience around assessing the built environment should not be minimalized, as ultimately policy change, infrastructure change, and cultural change at the community level is only going to move forward when the general citizenry become educated about the existing conditions and possible improvements within the walking/biking environment. The collective experience using the 
assessment tools can provide support to individuals who seek a more active and visible role in changing the transportation system.

If held somewhat intact, the collective group also can be a powerful representative constituency before city councils as a group of general citizens who have volunteered time to walk the streets, evaluate the walking/biking conditions, map the results, and provide recommendations for strategic improvements. An organized group with data, especially in map form, can be quite influential within the public policy process.

That said, the community-based collection of active transportation GIS is also inherently decentralized compared with the typical ways that transportation data is collected. Typically, spatial data is collected by local government (either in-house or through contract to a private firm), including the management, analysis, and distribution of that data. Involving citizens in developing active transportation GIS data, even in relatively discreet workshop settings, is a radically decentralized model that empowers and engages people in what is usually an invisible process by a select group of trained experts. So, relative to the status quo of transportation GIS data, the participatory workshop format is quite decentralized, but within a participatory and community-based GIS approach, the workshop model has several centralizing elements. Hence, the tools developed and distributed over the course of this OTREC project represent a Partially Centralized Partially Decentralized Expertise, or PCPDE, approach.

\subsection{DECENTRALIZED DISTRIBUTED EXPERTISE (DDE) MODEL}

Utilizing newer information technology via mobile phones and taking advantage of a widespread familiarity of Web maps (e.g., MapQuest or Google Maps) and navigation systems means that there may be an opportunity to decentralize active transportation data collection even further. In this approach, the entire responsibility of assessing current conditions could be put in the hands of individual citizens who collect data at their own leisure and based on their own utilization of the built environment.

In this DDE approach, individual citizens would be able to access a built environment assessment tool online and download it onto a personal mobile phone like an iPhone, Blackberry, or Android phone. They would then utilize the tool as they navigated their environment through the normal course of their days and activities. Some citizens may choose to purposefully utilize different routes in the course of a day, week, or month purposefully to add assessment data to the collective mix.

Data that is collected by individuals could be automatically uploaded to publicly accessible community mapping Web sites (Google Maps) where other citizens and public officials can see a variety of evaluations on how "friendly" different parts of a city are for biking and walking. It may be that as data is collected, automatic reports are sent to key public officials to alert them to issues or it may be that local advocacy groups seize on the data to help them in their work if the public agencies are unresponsive to the citizen evaluations. Ultimately, this built environment evaluation data could also feed into automated navigation systems for those wishing to navigate a city by active modes of transportation. 
Development and organization of an active transportation assessment tool for this type of decentralized approach would need to be different than the existing tools. Users in this case would be general citizens collecting data on their own time who would likely collect data only when confronted with a problem in their built environment. For example, a cyclist riding to work may become frustrated by a sewer grate with slats running parallel to the travel direction and may want to collect data on this deficiency, report it to the proper authorities, and map it for others to know about. In this situation, the user may not at all be interested in recording other attributes about the built environment such as number of lanes, traffic control devices, on-street parking or other elements found within tools such as the CSAT. So, to encourage a band of general citizens to collect data on the active transportation environment, the tools must be singlepurpose, easy to use, and quick to record the complaint or issue of the moment.

The ultimate benefit of this approach may not be in collecting a comprehensive set of attributes about every street segment and intersection, but in gathering a large number of data on specific barriers to the walking and biking environments. The tools become facilitators of barrier elimination rather than general descriptors of the existing environment. 


\subsection{CONCLUSION}

"Livability" has recently been declared one of four top priorities by the Secretary of the U.S. Department of Transportation (USDOT), and the USDOT, the Environmental Protection Agency (EPA), and the Department of Housing and Urban Development (HUD) have entered into an historic partnership to address the issue. Ultimately, this term refers to the quality of life within one's community and the ease, comfort, and joy with which one can access places s/he wants to go. For most Americans, their neighborhoods have been designed to predominantly accommodate the automobile, and more active forms of transportation such as walking and biking have been neglected. This neglect comes in the form both of the quality of the physical environment and in the land-use patterns that separate uses and make active transportation unfeasible.

That said, each neighborhood has destinations that could be theoretically within walking or biking distance even if a majority of trips would be more convenient if made by car. Many schools, friends' houses, or small-store goods and services are located in relative proximity. Yet even with short distances, in many neighborhoods across the country the physical environment is outright hostile to movement by foot or by bike.

The motivation of the work highlighted in this report is to help communities assess the quality of their built environment with respect to active modes of transportation and to help catalyze citizens to demand changes to their transportation infrastructure that allow a more complete set of transportation modes on their streets. Utilizing a participatory GIS approach, this work has developed the technical tools to assess the built environment, formatted the tools for use by a general citizen public, developed visual methods for analyzing collected data, and developed a participatory workshop format that helps facilitate community dialog about the conditions and opportunities for change in the built environment. Through workshops in communities across the country this format has proved successful, both in the decentralization of data collection to the general public and in the ability of community workshops around active transportation to lead to community capacity building for change.

However, the current model of using GIS-based systems for data collection and visualization has some significant limitations, namely cost. Developing, maintaining, and training based on a commercial GIS platform is expensive and time intensive and is only accessible by communities with significant subsidy. The software itself is expensive and the need for communities to host technical experts in the software adds cost to local efforts of engaging citizens to conduct selfassessments of their built environment. It is clear from the completed workshops that mapping citizens' observations is extremely powerful, which distinguishes this type of work from paper checklist assessment forms. However, the cost is a real impediment to widespread distribution and technology transfer. 
In order to take advantage of the power of data visualization through maps, as well as a general citizen interest in improving the active transportation environment, it seems that there may be an opportunity to utilize new mobile phone technology to accomplish similar goals. With new "smart phone" technology that exists in many phones at this moment, it may be possible to empower a general citizenry to assess their active transportation environment within the natural course of their day.

As data is collected, it could be electronically compiled and synthesized into community maps, which could then be utilized by public sector officials, community organizations or by individual citizens, depending on their need and desire regarding the walking and biking infrastructure. Such tools would take advantage of built-in features of the phones and would not necessarily need to interact at all with sophisticated GIS software. And on the user end, access to the tools could be easy and familiar.

Developing such tools, however, presents some trade-offs relative to the more intensive workshop format pursued thus far. Citizen engagement may be more widespread, but assessment may be much more shallow. Citizens may be more interested in only identifying barriers instead of all aspects of the built environment. And in an unstructured, massively distributed and decentralized approach to active transportation data collection, it is unclear who will do what with the data once collected.

Nonetheless, utilization of online maps and using phones for non-phone applications are almost ubiquitously making a transition from workshop-based, participatory GIS data collection to an individual, democratized approach - an opportunity that seems to be worth pursuing. It may be, in fact, that through empowering the general citizenry to assess their local built environment with respect to active transportation, in a relatively short amount of time we may be able to have a national walking and biking map that includes data at the scale of interest to these forms of transportation.

This transition - from a centrally located GIS with a facilitated, participatory data gathering process to one that uses more accessible Web-mapping platforms and where data is collected by a wider public in a less facilitated manner - is a significantly different process in many ways. Insofar as each person views their environment differently, online and mobile phone Webmapping provide the potential to aggregate evaluations from multiple citizens in a format that is accessible for a general public, policy makers, and city staff responsible for a functional multimodal infrastructure. Such a mobile mapping tool explores the potential of how emerging mobile technology can be harnessed within a planning context to articulate a localized vision of complete streets.

It may be that a mobile phone-based approach to assessing the built environment could energize large numbers of citizens across the country to take the USDOT Secretary's interest in "livability" and apply it in meaningful ways all across the country. This would help the nation transition from an urban form dependent on automobiles to one that offers more comprehensive transportation decisions that include walking and biking, the healthy, nonpolluting and congestion-reducing modes of transportation. 
P.O. Box 751

Portland, OR 97207

www.otrec.us

OTREC is dedicated to stimulating and conducting collaborative multi-disciplinary research on multi-modal surface transportation issues, educating a diverse array of current practitioners and future leaders in the transportation field, and encouraging implementation of relevant research results. 